B-CELL RESPONSES

\section{AIDing diversity}

Of humans, frogs, sharks and chickens, which is the odd one out? If you are interested in B cells, the answer is chickens - the first three animals use somatic hypermutation to diversify the variable $(V)$ regions of their rearranged antibody genes, whereas chickens, together with pigs and rabbits, use gene conversion. Two groups have now shown that a putative RNA editing enzyme - activationinduced cytidine deaminase (AID) - essential for somatic hypermutation and immunoglobulin classswitch recombination is also required for gene conversion.

It is unclear why some species use somatic hypermutation and others use gene conversion. The processes are very different - somatic hypermutation involves the introduction of untemplated single base-pair alterations, whereas in gene conversion, new sequences are copied from nearby pseudogenes. However, it has been shown recently that when gene conversion is blocked in a chicken B-cell line, somatic hypermutation can occur instead, indicating that the two processes might be linked mechanistically.

The two new studies made use of the chicken B-cell line DT40, which undergoes gene conversion spontaneously. Hiroshi Arakawa and colleagues, reporting in Science, used a variant of this cell line with a frameshift mutation in its rearranged $V$ segment that does not, therefore, express surface immunoglobulin (IgM). Gene conversion can repair the mutation, leading to the expression of surface IgM. The rate of reversion provides a quick

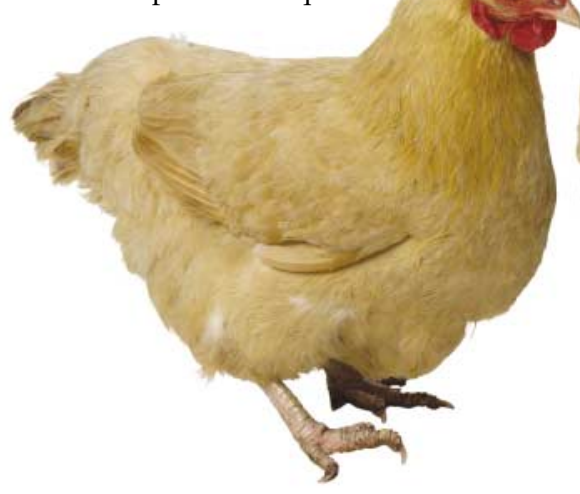

and easy measure of gene conversion. $A I D$ was knocked out by gene targeting to create $A I D^{-/-}$DT40 cells. Subclones were expanded for 18 days then analysed for surface IgM expression. The reversion rate in $A I D^{-1-}$ cells was reduced by at least 100 -fold, and sequencing confirmed that this was due to an absence of gene conversion.

Reuben Harris and colleagues also generated $\mathrm{AID}^{-/-}$cells, but in an $\mathrm{IgM}^{+}$ DT40 cell line. The cells were expanded for 40 days, then $\operatorname{IgM}^{\text {low }}$ cells were sorted and their $V$ genes sequenced. None of the $89 \mathrm{AID}^{-1-}$ cells analysed had undergone gene conversion, whereas gene-conversion events were detected in more than one-third of the $A I D^{+/+}$cells.

These studies promote AID to the position of master controller of antibody gene modifications. The mechanisms of somatic hypermutation, gene conversion and class-switch recombination are unknown; however, it has been proposed that DNA breaks (double- or single-stranded) might be pivotal to all three processes. Harris et al. conclude by predicting, "it is likely that AID is involved in the formation of an initiating DNA lesion common to switch recombination, hypermutation and gene conversion". Jennifer Bell

\section{(29) References and links} ORIGINAL RESEARCH PAPERS Arakawa, $\mathrm{H}$., Hauschild, J. \& Buerstedde, J. M. Requirement of the activation-induced deaminase (AID) gene for immunoglobulin gene conversion. Science $\mathbf{2 9 5}$, 1301-1306 (2002) | Harris, R. S. et al. Immunoglobulin $\mathrm{V}$ gene conversion in a cultured B-cell line is dependent upon AID. Curr. Biol. 2002 February 11 (DOI 10.1016/S0960982202007170).

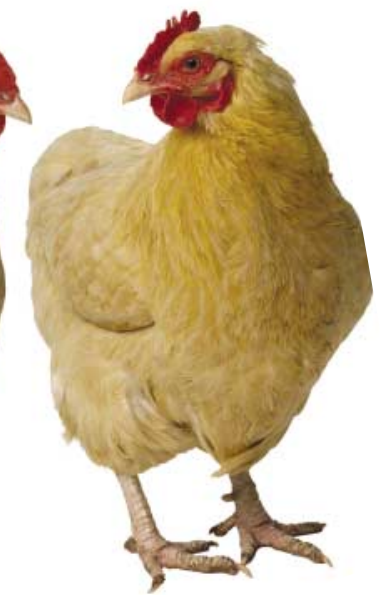

\section{IN BRIEF}

\author{
VACCINES
}

Adaptive immune response of $\mathrm{V} \gamma 2 \mathrm{~V} \delta 2^{+} \mathrm{T}$ cells during mycobacterial infections.

Shen, Y. et al. Science 295, 2255-2258 (2002)

Correlates of protection for tuberculosis in humans remain poorly characterized, and the role of $\mathrm{V} \gamma 2 \mathrm{~V} \delta 2^{+} \mathrm{T}$ cells - the major human $\gamma \delta$ T-cell population - is not well documented. Shen et al. show that $\mathrm{V} \gamma 2 \mathrm{~V} \delta 2^{+} \mathrm{T}$ cells in macaques proliferate in response to immunization with BCG. BCG-vaccinated macaques developed protective immunity against a fatal form of tuberculosis, which coincided with the expansion of alveolar $\mathrm{V} \gamma 2 \mathrm{~V} \delta 2^{+} \mathrm{T}$-cell populations. So, $\mathrm{V} \gamma 2 \mathrm{~V} \delta 2^{+} \mathrm{T}$ cells can develop memory responses and vaccines that target $\mathrm{V} \gamma 2 \mathrm{~V} \delta 2^{+} \mathrm{T}$ cells might be useful.

\section{VACCINES}

Efficient delivery of peptides to APC by use of MHC-class-II-specific troy-bodies.

Lunde, E. et al. J. Immunol. 168, 2154-2162 (2002)

Generating robust $\mathrm{T}$-cell responses remains a challenge for vaccine development. Here, MHC-class-II-specific antibodies were engineered to contain peptide epitopes from various model antigens within their constant regions. These 'troy-bodies' were shown to target the peptide to antigen-presenting cells, including $\mathrm{B}$ cells, macrophages and dendritic cells. In vivo, specific T-cell activation was 1,000-10,000-fold greater with troy-bodies than with native protein or peptide alone.

\section{AUTOIMMUNITY}

\section{Attenuated experimental autoimmune} encephalomyelitis in Eta-1/ostepontin-deficient mice.

Jansson, M. et al. J. Exp. Med. 168, 2096-2099 (2002)

T-helper $1\left(\mathrm{~T}_{\mathrm{H}} 1\right)$ responses have been implicated in the pathogenesis of multiple sclerosis (MS). Jansson et al. investigated the role of the $\mathrm{T}_{\mathrm{H}}$ 1-promoting cytokine Eta-1 in the development of experimental autoimmune encephalomyelitis (EAE), an animal model of MS. Eta- $1^{-1-}$ and wild-type mice were equally susceptible to the induction of EAE. However, Eta- $1^{-/-}$mice developed less severe pathology, had diminished Th1 responses and recovered quicker than wild-type mice.

\section{T-CELL DEVELOPMENT}

Role for CCR7 ligands in the emigration of newly generated T lymphocytes from neonatal thymus. Ueno, T. et al. Immunity 16, 205-218 (2002)

The developmental stages through which T cells pass in the thymus are well defined, but it is unclear what controls the emigration of $\mathrm{T}$ cells from the thymus. Previous studies have implicated chemokine signals in this process. By adding chemokines to fetal thymic organ cultures, and analysing thymic emigration in mice that are deficient or neutralized for certain chemokines and/or chemokine receptors, the authors highlight the importance of a CCL19- and CCR7-dependent pathway of thymic emigration. 